\title{
Correction to: The interface between child/adolescent and adult mental health services: results from a European 28-country survey
}

\author{
Giulia Signorini $^{1}$ (C) Swaran P. Singh ${ }^{2} \cdot$ Vlatka Boricevic Marsanic $^{3} \cdot$ Gwen Dieleman $^{4} \cdot$ Katarina Dodig-Ćurković $^{5}$. \\ Tomislav Franic ${ }^{6}$. Suzanne E. Gerritsen ${ }^{4}$. James Griffin ${ }^{7}$. Athanasios Maras ${ }^{4,8}$ • Fiona McNicholas . $^{9,10,11,12}$. \\ Lesley O'Hara ${ }^{13}$. Diane Purper-Ouakil ${ }^{14}$ - Moli Paul ${ }^{2}$. Frederick Russet ${ }^{14} \cdot$ Paramala Santosh $^{15,16,17}$. \\ Ulrike Schulze ${ }^{18}$. Cathy Street ${ }^{2} \cdot$ Sabine Tremmery ${ }^{19,20} \cdot$ Helena Tuomainen $^{2} \cdot$ Frank Verhulst $^{4} \cdot$ Jane Warwick $^{7}$. \\ Giovanni de Girolamo ${ }^{1}$ - for the MILESTONEConsortium
}

Published online: 13 March 2018

(c) Springer-Verlag GmbH Germany, part of Springer Nature 2018

\section{Correction to: European Child \& Adolescent Psychiatry https://doi.org/10.1007/s00787-018-1112-5}

The original version of this article contained an error in Table 1. The correct table is presented below:

The original article has been corrected.

The original article can be found online at https://doi.org/10.1007/ s00787-018-1112-5.

Giulia Signorini

gsignorini@fatebenefratelli.eu

1 Psychiatric Epidemiology and Evaluation Unit, Saint John of God Clinical Research Centre, Brescia, Italy

2 Mental Health and Wellbeing, Warwick Medical School, University of Warwick, Coventry, UK

3 Psychiatric Hospital for Children and Youth Zagreb, Zagreb, Croatia

4 Erasmus University Medical Centre, Rotterdam, Netherlands

5 Unit for Child and Adolescent Psychiatry, School of medicine, University Health Center in Osijek, Osijek, Croatia

6 Department of Psychiatry, Clinical Hospital Center Split, Split, Croatia

7 Warwick Clinical Trials Unit, Warwick Medical School, University of Warwick, Coventry, UK

8 Yulius Academy, Rotterdam, Netherlands

9 Department of Child and Adolescent Psychiatry, SMMS UCD, Belfield, Dublin 4, Ireland
10 Geary Institute, University College Dublin, Belfield, Dublin 4, Ireland

11 Department of Child Psychiatry, Our Lady's Hospital for Sick Children, Crumlin, Dublin 12, Ireland

12 Lucena Clinic SJOG, Rathgar, Dublin 6, Ireland

13 Saint John of God Research Foundation, Stillorgan, Co. Dublin, Ireland

14 Child and Adolescent Psychiatry Unit (MPEA1), CHU Montpellier-St Eloi Hospital, Montpellier, France

15 Department of Child and Adolescent Psychiatry, King's College London, Institute of Psychiatry, Psychology and Neuroscience, London, UK

16 National and Specialist Child and Adolescent Mental Health Services, Centre for Interventional Paediatric Psychopharmacology and Rare Diseases (CIPPRD), Maudsley Hospital, London, UK

17 HealthTracker Ltd, Gillingham, UK

18 Department of Child and Adolescent Psychiatry/Psychotherapy, University of Ulm, Ulm, Germany

19 Department of Neurosciences, Child and Adolescent Psychiatry, University of Leuven, Leuven, Belgium

20 Department of Child and Adolescent Psychiatry, University Hospitals Leuven, Leuven, Belgium 
Table 1 Estimated \% of CAMHS users anticipated to need transition to AMHS care by estimated \% of AMHS users with previous contact with CAMHS (under 30 years of age)

\begin{tabular}{|c|c|c|c|c|c|c|}
\hline & \multicolumn{6}{|c|}{ Estimated \% of CAMHS users with AMHS care needs as they age } \\
\hline & & $0-24 \%$ & $25-49 \%$ & $50-74 \%$ & $75-100 \%$ & \\
\hline \multirow{9}{*}{ 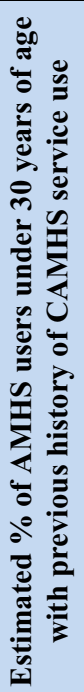 } & $10 \%$ & Greece, Poland & Portugal & & & 3 \\
\hline & $20 \%$ & Cyprus, Italy, Slovenia, & $\begin{array}{l}\text { Austria, Ireland, } \\
\text { Romania }\end{array}$ & Malta & Netherlands & 8 \\
\hline & $30 \%$ & & $\begin{array}{l}\text { Bulgaria, Croatia, } \\
\text { Germany, Latvia, } \\
\text { Luxembourg }\end{array}$ & & & 5 \\
\hline & $40 \%$ & Hungary & Sweden & & & 2 \\
\hline & $50 \%$ & Denmark & Finland & France, Lithuania & & 4 \\
\hline & $60 \%$ & Estonia & & Spain & & 2 \\
\hline & $70 \%$ & Slovakia & & & & 1 \\
\hline & $\begin{array}{c}\text { Not } \\
\text { Available }\end{array}$ & & Czech Republic & Belgium, UK & & 3 \\
\hline & & 9 & 12 & 6 & 1 & 28 \\
\hline
\end{tabular}

